\title{
Adherence to Dietary Recommendations, Nutrient Intake Adequacy and Diet Quality among Pediatric Cystic Fibrosis Patients: Results from the GreeCF Study
}

\author{
Dimitrios Poulimeneas 1,2®, Maria G. Grammatikopoulou ${ }^{3}$, Panagiota Devetzi ${ }^{3,4}$, \\ Argyri Petrocheilou 5 (1), Athanasios G. Kaditis 5,6, Theodora Papamitsou 7,*, \\ Stavros E. Doudounakis ${ }^{5}$ and Tonia Vassilakou ${ }^{1, *(D)}$ \\ 1 Department of Public Health Policy, School of Public Health, University of West Attica, 196, \\ Alexandras Avenue, GR-11521 Athens, Greece; dpoul@hua.gr \\ 2 Department of Nutrition and Dietetics, Harokopio University, E. Venizelou 70, GR-17671 Athens, Greece \\ 3 Department of Nutritional Sciences \& Dietetics, Faculty of Health Sciences, International Hellenic University, \\ Alexander Campus, GR-57001 Thessaloniki, Greece; maria@ihu.gr (M.G.G.); panagiwtadv@gmail.com (P.D.) \\ 4 Faculty of Biotechnology, Universidade Católica Portuguesa, Rua de Diogo Botelho, 1327, \\ 4169-005 Porto, Portugal \\ 5 Cystic Fibrosis Department, Agia Sophia Children's Hospital, Thivon 1, GR-11527 Athens, Greece; \\ apetroch@gmail.com (A.P.); kaditia@hotmail.com (A.G.K.); stavrosdoudounakis@yahoo.com (S.E.D.) \\ 6 Division of Pediatric Pulmonology and Sleep Disorders Laboratory, First Department of Pediatrics, \\ National and Kapodistrian University of Athens School of Medicine and Aghia Sophia Children's Hospital, \\ Thivon 1, GR-11527 Athens, Greece \\ 7 Laboratory of Histology and Embryology, Medical School, Faculty of Health Sciences, Aristotle University \\ of Thessaloniki, University Campus, GR-54124 Thessaloniki, Greece \\ * Correspondence: thpapami@auth.gr (T.P.); tvasilakou@uniwa.gr (T.V.)
}

Received: 20 September 2020; Accepted: 9 October 2020; Published: 13 October 2020

check for updates

\begin{abstract}
Nutrition is an important component of cystic fibrosis (CF) therapy, with a high-fat diet being the cornerstone of treatment. However, adherence to the dietary recommendations for CF appears suboptimal and burdensome for most children and adolescents with CF, leading to malnutrition, inadequate growth, compromised lung function and increased risk for respiratory infections. A cross-sectional approach was deployed to examine the degree of adherence to the nutrition recommendations and diet quality among children with CF. A total of 76 children were recruited from Aghia Sophia's Children Hospital, in Athens, Greece. In their majority, participants attained their ideal body weight, met the recommendations for energy and fat intake, exceeding the goal for saturated fatty acids consumption. Carbohydrate and fiber intake were suboptimal and most participants exhibited low or mediocre adherence to the Mediterranean diet prototype. It appears that despite the optimal adherence to the energy and fat recommendations, there is still room for improvement concerning diet quality and fiber intake.
\end{abstract}

Keywords: Mediterranean diet; dietary recommendations; nutrition; medical nutrition therapy; growth; malnutrition; pediatric patients; nutritional assessment; pulmonological disease; nutritional status; lung disease

\section{Introduction}

Cystic fibrosis (CF) is a genetic disease, affecting primarily the respiratory and gastrointestinal systems. Treatment includes daily medication, enzymes, adherence to a high-fat diet, vitamin oral 
nutrient supplements (ONS), as well as physiotherapy and respiratory exercises. Treatment adherence is important to maintain health and prolong life expectancy, however, compliance to the therapy appears to be problematic, especially as far as diet, exercise and chest physiotherapy are concerned [1]. According to research, a great proportion of CF patients fail to comply to the general, pancreatic enzyme replacement therapy (PERT), vitamin prescription and respiratory exercises due to lack of motivation, time and interest [2-4], whereas 11\% of patients homozygous for the F508del-Cystic Fibrosis Transmembrane conductance Regulator (CFTR) mutation do not adhere to the Lumacaftor-ivacaftor medication prescription [5]. In particular, persistent adherence appears to be the most problematic one, with very few patients exhibiting periods of complete adherence at some point in their life [6].

As far as adolescent patients are concerned, most do not comply to the daily vest therapy [7] and chest physiotherapy [8], and more than half are considered as low PERT adherers [8,9]. Nutrition-wise, research appears unanimous on the fact that more than half of the children with CF demonstrate suboptimal compliance to the prescribed vitamins supplementation $[8,10]$. Low adherence to the dietary recommendations in particular, may result in malnutrition, with immediate effects on the immune system and lung function, and an increased risk for infections and hospitalization [11-13]. Due to the unique psychological characteristics of adolescents with chronic disease and their frequent failure to conform to therapy, compliance surveillance is important in identifying those at need for more counselling and close monitoring [14,15].

The aim of the present cross-sectional study was to assess diet quality and adherence to the dietary guidelines for $\mathrm{CF}$ among pediatric patients.

\section{Materials and Methods}

\subsection{Sample Recruitment}

Children and adolescent with CF were recruited from outpatients of the Clinic for Cystic Fibrosis, situated in Aghia Sophia Children's Hospital, Athens, Greece. Details concerning the recruitment and ethical permission have been previously reported [16,17]. Characteristics of the patients are presented in Table 1.

Table 1. Sample characteristics $(n=76)$.

\begin{tabular}{cccc}
\hline Patient Characteristics & Boys $(\boldsymbol{n}=\mathbf{3 2})$ & Girls $(\boldsymbol{n}=4 \mathbf{4})$ & $p$ Value \\
\hline Age (years) & $12.4 \pm 3.8$ & $11.6 \pm 4$ & 0.376 \\
\hline Adolescents $(\%)$ & 50 & 31.8 & 0.109 \\
\hline Body weight $(\mathrm{kg})$ & $44.5 \pm 18.3$ & $37.4 \pm 12.8$ & 0.062 \\
\hline Stature $(\mathrm{m})$ & $1.49 \pm 0.2$ & $1.41 \pm 0.18$ & 0.1 \\
\hline BMI $\left(\mathrm{kg} / \mathrm{m}^{2}\right)$ & $19.1 \pm 3.5$ & $18.2 \pm 2.7$ & 0.199 \\
\hline FEV1\% & $96.7 \pm 18.6$ & $99.1 \pm 21.9$ & 0.614 \\
\hline Pancreatic Insufficiency (\%) & 81.3 & 90.9 & 0.22 \\
\hline Liver disease $(\%)$ & 12.5 & 6.8 & 0.398 \\
\hline CFRD $(\%)$ & 3.1 & 6.8 & 0.477 \\
\hline Presence of Meconium Ileus $(\%)$ & 31.3 & 9.1 & 0.014 \\
\hline NBS diagnosis (\%) & 6.3 & 15.9 & 0.198 \\
\hline HomoF508del $(\%)$ & 34.4 & 45.5 & 0.332 \\
\hline HeteroF508del $(\%)$ & 46.9 & 40.9 & 0.604 \\
\hline P.Aeruginosa chronic infection $(\%)$ & 12.5 & 11.4 & 0.88 \\
\hline S.Aureus chronic infection $(\%)$ & 0 & 2.3 & 0.391 \\
\hline Body Mas & & & \\
\hline
\end{tabular}

BMI, Body Mass Index; FEV1, Forced expiratory volume in 1 sec; CFRD, Cystic Fibrosis related diabetes; NBS, newborn screening. 


\subsection{Anthropometric Indices}

Anthropometry was conducted during morning hours, with light clothing and bare feet. Body weight was measured at the nearest $0.1 \mathrm{~kg}$ (SECA 874 portable digital scale, Hamburg, Germany) and height to the nearest $0.5 \mathrm{~cm}$ (SECA 214 portable stadiometer, Hamburg, Germany), and then body mass index (BMI) was computed. Height-for-age (HAZ) and BMI-for age (BAZ) z-scores were calculated for each patient, based on the Centers for Disease Control (CDC) growth charts [18]. The CDC growth charts were selected on the basis of (i) better comparability with the US and the European Cystic Fibrosis registries, and (ii) our previous observation that the CDC growth charts provide similar estimations of nutritional status compared with the World Health Organization and International Obesity Task Force charts $[17,19,20]$. According to the BAZ, patients were classified as underweight (BAZ $<-2.0$ ), of normal body weight $(-2.0 \leq \mathrm{BAZ}<1.0)$, overweight or obese (BAZ $\geq 1.0$, and $\mathrm{BAZ} \geq$ 2.0, respectively). CF specific classification was used to assess ideal body weight (IBW) attainment $(\mathrm{BAZ} \geq 0.0)$ and possible nutritional failure $(\mathrm{BAZ}<-1.04)$ [21]. Children with a $\mathrm{HAZ}<-2.0$ were considered chronically malnourished (stunted).

\subsection{Dietary Intake, Diet Quality and Adherence to Diet Treatment}

Two non-consecutive $24 \mathrm{~h}$ dietary recalls were completed for each participant, within a period of 14 calendar days, through interview with an experienced dietician (D.P.) Given that food records are associated with an increased responder burden and higher chances of incorporating changes in the usual eating behavior, we opted for using multiple $24 \mathrm{~h}$ dietary recalls [22,23]. For children aged below 9 years old, parental consensus and help in competing the $24 \mathrm{~h}$ recalls were sought. Records were then analyzed for total energy intake (TEI), macro- and micro-nutrient intake using the Food Processor software (ESHA, Portland, Oregon).

Diet quality was assessed with the KIDMED questionnaire [24], evaluating adherence to the Mediterranean diet (MD) prototype. The questionnaire is based on 16 questions concerning the frequency of consumption of foods typical to the Mediterranean region, against foods considered as characteristic of the Western diet. The KIDMED is widely used in epidemiology (based on the number of citations), providing reliable estimates of adherence to the MD [25], and has previously been translated and used in the Greek population [26]. Scores $<4$ are indicative of low adherence and poor diet quality, scores between 4 and 7 are indicative of mediocre diet quality and scores exceeding 8 are observed among high MD adherers [24].

Dietary intake data were then compared to the Nutrition Guidelines for Cystic Fibrosis in Australia and New Zealand [27], which are considered as the most "complete" CF dietary guidelines in terms of CF-specific recommendations [28]. Participants were categorized according to those adhering and/or exceeding dietary recommendations, or not. The adequate intake of nutrients not included in the aforementioned guidelines was assessed through the relevant population reference intake (PRI) level for each nutrient set by the European Food Safety Authority [29].

\subsection{Ethical Approval}

The parents/guardians of all subjects provided informed consent for inclusion before participating in the study. The study was conducted in accordance with the Declaration of Helsinki, and the protocol was approved by the Ethics Committees of both Aghia Sophia Children's Hospital, and University of West Attica (reference number 16084/14-07-15).

\subsection{Statistical Analyses}

Data distribution was graphically explored with Q-Q plots. Continuous variables are presented as means \pm standard deviation (for normally distributed variables), or medians (1st and 3rd quartile) (for non-normally distributed variables). Categorical variables are presented as relative frequencies and percentages. Differences between continuous variables were assessed with independent t-test (for 
normally distributed variables), or the Mann-Whitney U test (non-normally distributed variables). Chi-square or the Fisher's exact test was employed to explore differences between categorical variables. The relatively small number of participants did not allow for the performance of regression analyses.

The level of significance was set at $\alpha=0.05$. All analyses were carried out on SPSS version 25.0 (IBM, SPSS Inc., Chicago, IL, USA).

\section{Results}

\subsection{Anthropometric Data}

In the total sample of girls, and boys, mean values of height and BMI z-scores indicated adequate growth. In particular, for girls, mean BAZ was calculated at $0.02 \pm 1.10$, and for boys mean BAZ reached $0.01 \pm 1.16$ ( $p=0.785$ for between sexes comparison). Height $z$-scores were considered optimal, although mean values were lower than the 50th percentile (girls: $-0.19 \pm 1.22$ and boys: $-0.40 \pm 0.88$, $p=0.394$ ). Body weight classification is demonstrated in Figure 1. While nutritional failure was prevalent in $1 / 5$ of both the boys and the girls, the vast majority of the sample attained adequate weight status, with $72 \%$ of the boys and $84 \%$ of the girls being classified as normoweight, and $60 \%$ of participants from both sexes having reached the target CF-specific BMI. Stunting prevailed in few participants. No significant difference was detected in body weight and height status between boys and girls ( $p>0.05$ for all comparisons).

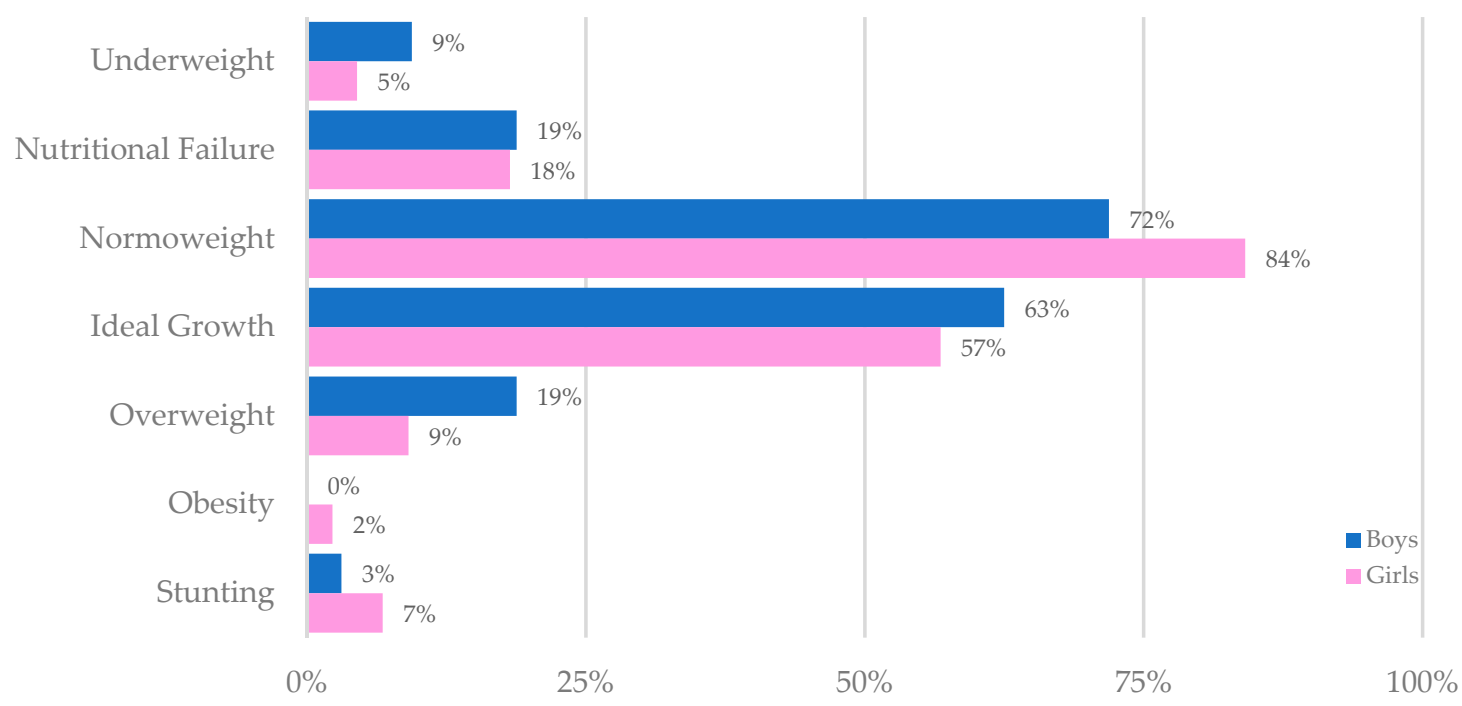

Figure 1. Body weight and height status classification of participants.

\subsection{Adequacy in the Dietary Intake}

All of the participating children and adolescents (100\%) exceeded the estimated energy requirement (EER) intake (Table 2). Protein and fat were adequately consumed by $84.4 \%$ and $87.5 \%$ of the boys, and $75 \%$ and $88.6 \%$ of the girls, respectively. On the other hand, carbohydrate and fiber intakes was suboptimal, with only $1 / 3$ of the patients meeting the respective guidance. None of the participants achieved the recommended intake for saturated fatty acids (SFA), with all exceeding the suggested daily consumption levels. Fiber intake was adequate for a mere $40.6 \%$ of the boys and $45.5 \%$ of the girls, respectively. 
Table 2. Dietary assessment of girls and boys with cystic fibrosis and compliance with the recommendations *.

\begin{tabular}{|c|c|c|c|c|c|c|c|}
\hline \multirow{3}{*}{ Energy and Nutrients } & \multicolumn{3}{|c|}{ Recorded Daily Dietary Intake } & \multirow{3}{*}{ Recommendation } & \multirow{2}{*}{\multicolumn{3}{|c|}{$\begin{array}{c}\text { Compliance with the Recommendations } \\
\text { Meeting and/or Exceeding Recommendations }\end{array}$}} \\
\hline & \multirow{2}{*}{$\begin{array}{l}\text { Boys } \\
(n=32)\end{array}$} & \multirow{2}{*}{$\begin{array}{l}\text { Girls } \\
(n=44)\end{array}$} & \multirow{2}{*}{$p$ Value } & & & & \\
\hline & & & & & $\begin{array}{l}\text { Boys } \\
(\%)\end{array}$ & $\begin{array}{l}\text { Girls } \\
(\%)\end{array}$ & $p$ Value \\
\hline Total Energy intake $(\mathrm{kcal} / \mathrm{d})$ & $2623 \pm 654$ & $2486 \pm 738$ & 0.401 & & - & - & - \\
\hline TEI (\% EER) & $122 \pm 47$ & $130 \pm 42$ & 0.430 & $110-200 \%$ EER & 100 & 100 & - \\
\hline Protein (\% TEI) & $19.7 \pm 7.0$ & $18.0 \pm 5.5$ & 0.248 & $15-20 \%$ TEI & 84.4 & 75.0 & 0.322 \\
\hline Carbohydrate (\% TEI) & $37.7 \pm 8.9$ & $37.9 \pm 10.2$ & 0.912 & $40-65 \%$ TEI & 37.5 & 38.6 & 0.920 \\
\hline Total Fat $(\mathrm{g} / \mathrm{d})$ & $127 \pm 38$ & $123 \pm 40$ & 0.677 & $\geq 100 \mathrm{~g}$ & 71.9 & 72.7 & 0.935 \\
\hline Total Fat (\% TEI) & $43.8 \pm 7.6$ & $45.1 \pm 8.9$ & 0.484 & $35-40 \%$ TEI & 87.5 & 88.6 & 0.880 \\
\hline Saturated Fat (\% TEI) & $15.1 \pm 3.1$ & $16.5 \pm 5.0$ & 0.167 & As low as possible & - & - & - \\
\hline Dietary Fiber $(\mathrm{g} / \mathrm{d})$ & $13.5(10.7,17.2)$ & $13.1(7.9,22.9)$ & 0.768 & $14-30 \mathrm{~g}$ & 40.6 & 45.5 & 0.675 \\
\hline Vitamin A (RE/d) & $222(73,446)$ & $314(127,514)$ & & $\begin{array}{c}4-6 \text { yr: } 300 \text { RE; } 7-10 \text { yrs: } 400 \text { RE; } \\
\text { 11-14 yr: } 600 \mathrm{RE;} \\
\geq 15 \text { yrs: } 750 \text { RE (boys), } 650 \text { RE (girls). }\end{array}$ & 45.5 & 60.0 & 0.319 \\
\hline Vitamin D $(\mu \mathrm{g} / \mathrm{d})$ & $5.7(3.5,7.6)$ & $5.7(3.8,7.6)$ & & $15 \mu \mathrm{g}$ & 4.5 & 0.0 & 0.222 \\
\hline Vitamin E (mg/d) & $4.5(6.6,9.1)$ & $7.8(4.9,9.6)$ & & $\begin{array}{l}3-9 \text { yrs: } 9 \mathrm{mg} ; \\
\geq 10 \text { yrs: } 13 \mathrm{mg} \text { (boys), } 11 \mathrm{mg} \text { (girls). }\end{array}$ & 20.5 & 9.4 & 0.191 \\
\hline Iron (mg/d) & $14.4(10.6,19.9)$ & $18.3(10.2,29.5)$ & 0.449 & $\begin{array}{l}\text { 4-8 yrs: } 10 \mathrm{mg} \text {; 9-13 yrs: } 8 \mathrm{mg} ; \\
\geq 14 \text { yrs: } 11 \mathrm{mg} \text { (boys), } 15 \mathrm{mg} \text { (girls). }\end{array}$ & 71.9 & 61.4 & 0.340 \\
\hline Magnesium (mg/d) & $237(181,329)$ & $246(207,289)$ & 0.628 & $\begin{array}{l}4-8 \text { yrs: } 130 \mathrm{mg} ; 9-13 \text { yrs: } 240 \mathrm{mg} ; \\
\geq 14 \text { yrs: } 410 \mathrm{mg} \text { (boys), } 360 \mathrm{mg} \text { (girls). }\end{array}$ & 35.5 & 64.5 & 0.332 \\
\hline Calcium (mg/d) & $1227(802,1530)$ & $1271(895,1551)$ & 0.474 & $\begin{array}{l}4-8 \text { yrs: } 0.7 \mathrm{~g} ; 9-11 \text { yrs: } 1 \mathrm{~g} ; \\
12-18 \text { yrs: } 1.3 \mathrm{~g} \text {. }\end{array}$ & 71.9 & 70.5 & 0.893 \\
\hline Sodium $(\mathrm{mg} / \mathrm{d})+$ & $2898(2043,4080)$ & $2936(2079,3524)$ & 0.925 & Children: $1-4$ g; Adolescents: 6 g. & 53.1 & 63.6 & 0.357 \\
\hline Zinc (mg/d) & $14.8(7.8,19.0)$ & $13.1(9.9,18.0)$ & 0.958 & $\begin{array}{c}4-8 \text { yrs: } 4 \mathrm{mg} ; 9-13 \text { yrs: } 6 \mathrm{mg} ; \\
\geq 14 \text { yrs: } 13 \mathrm{mg} \text { (boys), } 7 \mathrm{mg} \text { (girls). }\end{array}$ & 68.8 & 79.5 & 0.283 \\
\hline
\end{tabular}

EER, estimated energy requirements; RE, Retinol equivalents; TEI, Total Energy Intake; yrs, years; ${ }^{*}$ Compared against the Nutrition Guidelines for Cystic Fibrosis in Australia and New

Zealand [27]. + refers to sodium naturally occurring in foods. 
With regards to the fat-soluble vitamins' intake, small proportions of children met the recommended intake for vitamin D and vitamin $\mathrm{E}$, whereas vitamin $\mathrm{A}$ intake was adequate for $45.5 \%$ of the boys and $60 \%$ of the girls. With reference to the mineral intake, adequate consumption was observed by the majority of children concerning all examined minerals, with the exception of boys' magnesium intake which was suboptimal.

No differences were observed between sexes in the proportion of boys and girls failing within the dietary recommendations, or those exceeding the recommended intakes.

Dietary intake data were also analyzed according to the attainment of IBW and the diagnosis of nutritional failure (data not shown). Children categorized below the 50th percentile of BMI consumed more TEI compared to those exceeding the $50^{\text {th }}$ percentile, both in terms of crude energy intake $(2789 \pm 728$ vs. $2376 \pm 642 \mathrm{kcal} / \mathrm{day}, p=0.014)$ and expressed as a percentage $(\%)$ of the recommended intake (143.8 \pm 46.3 and vs. $115.5 \pm 38.6 \%$, respectively, $p=0.007)$. Consequently, more children under the 50th BMI percentile consumed a diet within the recommended levels for energy intake (77.4 vs. $53.3 \%, p=0.032$ ). No other differences were noted for other macro- or micro-nutrients. Children at nutritional failure (BMI $<15$ th percentile) did not demonstrate any differences in the TEI or nutrient intake as compared to the children with greater BMI. However, a marginal trend was revealed, demonstrating that fewer children with nutritional failure consumed adequate fat (expressed in $\mathrm{g}$ ) as compared to their heavier counterparts $(67.7 \%$ vs. $92.9 \%, p=0.058)$.

\subsection{Quality of the Dietary Intake-Mediterranean Diet Adherence}

Dietary quality indices are presented in Table 3. The majority of the patients adopted a diet of poor or moderate diet quality $(75 \%)$, whereas a trend for more boys achieving a mediocre score in the KIDMED, and more girls scoring high in diet quality was revealed. More boys than girls consumed food at fast food restaurants more than once per week ( $65.7 \mathrm{vs.} 37.5 \%, p=0.014)$, whereas a trend for more boys having dairy for breakfast than girls was present. The majority of participants scored low in questions regarding the core food groups of the Mediterranean dietary pattern, namely daily fruit and vegetables intake, and the frequency of consumption of fish, pulses and nuts within a week.

Table 3. Diet quality of children and adolescents with cystic fibrosis according to the KIDMED [24] score.

\begin{tabular}{|c|c|c|c|}
\hline KIDMED Components and Total Score & $\begin{array}{c}\text { Girls } \\
(n=44)\end{array}$ & $\begin{array}{c}\text { Boys } \\
(n=32)\end{array}$ & $p$ Value \\
\hline Takes a fruit or fruit juice each day (\%) & 58.3 & 71.4 & 0.220 \\
\hline Has a second fruit each day (\%) & 16.7 & 17.1 & 0.954 \\
\hline Has fresh or cooked vegetables regularly once/day (\%) & 62.5 & 54.3 & 0.452 \\
\hline Has fresh or cooked vegetables more than once/day (\%) & 14.6 & 20.0 & 0.515 \\
\hline Consumes fish regularly (at least $2-3 /$ week) $(\%)$ & 14.6 & 14.3 & 0.499 \\
\hline Goes $>1 /$ week to a fast food restaurant (hamburger) $(\%)$ & 37.5 & 65.7 & 0.014 \\
\hline Likes pulses and eats them $>1 /$ week $(\%)$ & 41.7 & 40.0 & 0.673 \\
\hline Consumes pasta or rice almost every day ( $\geq 5 /$ week) $(\%)$ & 100 & 97.1 & 0.239 \\
\hline Has cereals or grains (bread, etc.) for breakfast (\%) & 47.9 & 68.6 & 0.061 \\
\hline Consumes nuts regularly (at least 2-3/week) (\%) & 39.6 & 28.6 & 0.299 \\
\hline Uses olive oil at home (\%) & 97.9 & 94.3 & 0.381 \\
\hline Skips breakfast (\%) & 20.8 & 20.0 & 0.685 \\
\hline Has a dairy product for breakfast (yoghurt, milk, etc.) (\%) & 81.3 & 94.3 & 0.084 \\
\hline Has commercially baked goods or pastries for breakfast (\%) & 10.4 & 20.0 & 0.220 \\
\hline Takes two yoghurts and/or some cheese (40 g) daily (\%) & 93.8 & 88.6 & 0.402 \\
\hline Takes sweets and candy several times every day (\%) & 35.4 & 22.9 & 0.187 \\
\hline
\end{tabular}


Table 3. Cont.

\begin{tabular}{lccc}
\hline \multicolumn{1}{c}{ KIDMED Components and Total Score } & $\begin{array}{c}\text { Girls } \\
(\boldsymbol{n}=\mathbf{4 4})\end{array}$ & $\begin{array}{c}\text { Boys } \\
(\boldsymbol{n}=\mathbf{3 2})\end{array}$ & $\boldsymbol{p}$ Value \\
\hline KIDMED score & $5.7 \pm 2.6$ & $5.6 \pm 2.3$ & 0.860 \\
\hline Low * KIDMED score (\%) & 25.0 & 22.9 & 0.822 \\
\hline Moderate * KIDMED score (\%) & 43.8 & 62.9 & 0.085 \\
\hline High * KIDMED score (\%) & 31.3 & 14.3 & 0.074 \\
\hline
\end{tabular}

* Low KIDMED score was defined as $<4$, scores between 4 and 7 were considered as indicative of moderate diet quality and scores exceeding $>8$ were used to identify high Mediterranean diet adherers [24].

Girls scoring low in KIDMED were less likely to report an adequate fiber intake $(p=0.006)$; the reverse was true when girls scored high in $\operatorname{KIDMED}(p=0.014)$ (data not shown). Boys scoring high in the KIDMED questionnaire were more likely to consume fat adequately $(p=0.043)$ (data not shown). The KIDMED did not correlate with any dietary factor. No other differences were detected regarding diet quality and nutrient adequacy.

\section{Discussion}

The findings of the present study suggest that Greek school-aged children with CF adhere to a diet adequate in energy, protein and fat intake, that is mostly of low or moderate quality. At the same time, our observations suggest that there is room for improvement in terms of carbohydrate and fiber intake, as well as certain minerals and vitamins.

Relevant to energy intake, all of the examined children were found to consume a diet with an energy content $>110 \%$ of the estimated average energy intake for children. These findings are in line with a recent Australian study, indicating that children with CF consumed a diet with a median energy content of $158 \%$ of the recommended energy intake [30]. On the other hand, an early report showed that children with $\mathrm{CF}$ failed to meet recommendations regarding energy intake [31]. Some more recent data suggest that children with CF marginally met energy recommendations, even though they consumed more energy as compared to healthy controls [32]. These discrepancies may be explained by the different methods of dietary assessment employed in the aforementioned studies. Nevertheless, these differences in between earlier and more recent studies may also be indicative of the vast improvements in dietary counselling in children with CF that have been noted in the past 25 years. At the same time, as indicated by the body weight of participants herein, in their majority they consisted of well-nourished patients, given that for most attainment of IBW and physiological lung function was apparent. According to an Irish study, parents of children with CF often use IBW attainment as a criterion for the children's health status, influencing their approaches to the dietary management of the disease [33].

With regards to the macronutrient intake, the present sample consumed a diet high in fat, that was also adequate in protein. The latter is known to reduce muscle and bone mineral loss and is associated with improved survival [12]. An early clinical trial revealed that within a short period of supplementation, high protein intake was associated with increased whole-body protein synthesis rates among stunted children with CF [34]. In parallel, a diet high in protein appears to be highly anabolic, even in patients with CF recovering from exacerbations, or those with muscle loss [12]. According to Engelen [12], despite its importance, protein is often under-regarded in the dietary management of children with $\mathrm{CF}$, although that was not the case in our sample.

Adherence to a diet high in fat has been the cornerstone of CF treatment for more than 25 years [35]. In the present analysis, fat intake of most of the participants exceeded the recommended range between $35 \%$ and $40 \%$ of the daily energy consumption. Previous studies in children with CF have recorded fat intakes within the $30-35 \%$ range $[31,36,37]$, or even greater $[32,35,38]$, indicating a unanimous adherence to the fat intake recommendation. Nevertheless, the postulated problem in high-fat diets is the correspondingly elevated SFA content $[35,38]$ which, for more than 50 years, was considered as harmful for cardiovascular health. As a result of their high-fat diet, most children with CF have 
been reported to exceed the recommendations regarding SFA intake [32,35]. More recently, evidence of higher quality, including meta-analyses, contradicts this narrative, indicating that SFA intake has either positive, or null effect on cardiovascular health based on dose-response analyses $[39,40]$. On the other hand, children with CF often demonstrate essential fatty acid deficiencies, with some being non-responsive to supplementation treatment due to multiple potential impediments leading to malabsorption issues, indicating that the disease is associated with a cascade of health issues requiring adequacy in the intake of fat [41-43]. In parallel, despite the reported high intakes of fat, serum lipid levels are often within normal ranges, even among adults with CF who have adhered to a high-fat diet for a longer period of time [44]. Moreover, research on children has failed to associate fat intake to the lipidemic profile in CF [38], whereas on the other hand, it had been suggested that the high prevalence of hypertriglyceridemia observed in CF might be associated with an increased carbohydrate intake, and not the result of the high-fat diet [45]. Nevertheless, recommendations regarding the intake of SFA in CF retain the former low recommended SFA intake values, despite the existing evidence controversy and scientific debate [46,47].

Participants with CF exhibited a low mean carbohydrate intake. The positives of a low carbohydrate consumption are associated with the reduced sugar and refined cereals intake, whereas an important limitation stems from the often-inadequate fiber content of the diet. As a result, the fiber consumption of the participating children was indeed below recommendations for the majority of participants, with approximately $1 / 3$ of the sample fulfilling the daily intake goal. Previous studies have also highlighted the low fiber intake of children with CF as compared to their healthy peers [48], whereas many children with CF encounter digestive and gastrointestinal issues which might be related to low fiber intake [49]. An older Belgian study failed to associate fiber consumption to gastrointestinal complains and distal intestinal obstruction syndrome (DIOS) among children with CF [50], however, the design was cross-sectional, not allowing for the establishment of a causal relationship. Nevertheless, fiber is a common constituent of ready-to-use supplemental food (RUSF) for children with CF [51], indicating that fiber is regarded as a key nutrient, often consumed inadequately among children with CF.

With reference to micronutrients, mineral intakes have not received adequate attention in CF, in contrast with the fat-soluble vitamins, which are routinely assessed in serum and supplemented orally [52,53]. Our patients exhibited comparable micronutrient intake with an Australian pediatric cohort of CF [54]. While for most micronutrients, the Australian study reported somewhat higher intakes than those we recorded, the largest differences were observed for vitamin A and magnesium intakes. These findings are also in line with findings from the general healthy Greek children, that have reported insufficient intakes of vitamin A and magnesium [55,56].

The MD is a regional dietary pattern with numerous health benefits for the general and disease-specific population [57-60]. Adherence to the diet had been suggested as a prototype dietary pattern favorable for the management of CF [61]. Although randomized controlled trials and intervention studies on children with CF are yet to be undertaken, the ILERVAS project revealed that adherence to a combination of lifestyle interventions including MD and physical activity was associated with an improved lung function, including higher forced vital capacity (FVC) and forced expired volume (FEV1) in the first second [62]. In the present sample, most participants failed to adhere to the MD pattern, demonstrating low adherence. However, according to the literature, low adherence is also apparent in most children and adolescents inhabiting the Mediterranean region [63,64]. Furthermore, pediatric patients with CF have been known to endorse an energy-dense, yet nutrient-poor diet, that is indicative of a diet low in quality [30]. In the aging population with $\mathrm{CF}$, awareness is raised regarding cardiovascular risk. Low dietary quality has been independently associated with indices of poor cardiovascular health in apparently healthy children [65], whereas poor dietary indices contribute to the burden of disease into adulthood [66]. In light of the aforementioned findings, beyond energy and macronutrient intake, dietary counselling for CF should also advocate for a diet of higher quality, that also targets optimal micronutrient intake. 
Limitations of the study include its cross-sectional design and relatively small sample, recruited from one clinic only. Nevertheless, the clinic is the largest in Greece, situated in the capital, Athens, with the largest number of CF pediatric patients. Addition of a control group of healthy children could have allowed for comparisons of our cohort of CF patients with the general population, a lack we faced due to limited resources. Dietary intake was assessed by 2 non-consecutive dietary recalls. Two $24-h$ dietary recalls are widely used in large populational studies like the National Health and Nutrition Examination Survey (NHANES), alleviate the burden of the patients, the mode of delivery does not affect eating patterns, and are known to be valid methods for the assessment of children's dietary intake [23,67]. Cross-matching of dietary intake with biochemical data could have provided further insight in the association of dietary intake and health outcomes in CF. On the other hand, the present study consists of the first research item assessing MD in a CF population, adding more data to current knowledge on the nutritional status of children with CF.

\section{Conclusions}

In the majority, the examined children with $\mathrm{CF}$ receiving proper nutritional education and advice appear to be well-nourished, adhering to the majority of nutritional recommendations, while failing to meet the goal intakes for fiber and carbohydrate intake. A low adherence to the MD is revealed, indicating that there is still room for further improvement in terms of diet quality, which in turn could also attenuate micronutrient intake.

Author Contributions: Conceptualization, D.P. and T.V.; methodology, D.P.; formal analysis, D.P.; investigation, D.P., A.P., A.G.K. and S.E.D.; data curation, P.D.; writing-original draft preparation, D.P. and M.G.G.; writing-review and editing, D.P., M.G.G., P.D., T.P. and T.V.; supervision, M.G.G. and T.V.; project administration, T.V.; funding acquisition, T.P. All authors have read and agreed to the published version of the manuscript.

Funding: This research was funded by the "MSc in Health and Environmental Factors", Medical School, Aristotle University of Thessaloniki, Greece (Grant No: 97509).

Conflicts of Interest: The authors declare no conflict of interest.

\section{References}

1. Bernard, R.S.; Cohen, L.L. Increasing adherence to cystic fibrosis treatment: A systematic review of behavioral techniques. Pediatr. Pulmonol. 2004, 37, 8-16. [CrossRef] [PubMed]

2. Santuzzi, C.H.; Liberato, F.M.G.; Morau, S.A.C.; de Oliveira, N.F.F.; Nascimento, L.R. Adherence and barriers to general and respiratory exercises in cystic fibrosis. Pediatr. Pulmonol. 2020. [CrossRef] [PubMed]

3. Abbott, J.; Dodd, M.; Webb, A.K. Health perceptions and treatment adherence in adults with cystic fibrosis. Thorax 1996, 51, 1233-1238. [CrossRef] [PubMed]

4. Rouzé, H.; Viprey, M.; Allemann, S.; Dima, A.L.; Caillet, P.; Denis, A.; Poupon-Bourdy, S.; Camara, B.; Llerena, C.; Reix, P.; et al. Adherence to long-term therapies in cystic fibrosis: A French cross-sectional study linking prescribing, dispensing, and hospitalization data. Patient Prefer. Adherence 2019, 13, 1497-1510. [CrossRef]

5. Olivereau, L.; Nave, V.; Garcia, S.; Perceval, M.; Rabilloud, M.; Durieu, I.; Reynaud, Q. Adherence to lumacaftor-ivacaftor therapy in patients with cystic fibrosis in France. J. Cyst. Fibros. 2020, 19, 402-406. [CrossRef]

6. Sherman, A.C.; Simonton-Atchley, S.; Campbell, D.; Reddy, R.M.; O’Brien, C.E.; Guinee, B.; Wagner, L.D.; Anderson, P.J. Persistent Adherence to Airway Clearance Therapy in Adults with Cystic Fibrosis. Respir. Care 2019, 64, 778-785. [CrossRef]

7. Benoit, C.M.; Christensen, E.; Nickel, A.J.; Shogren, S.; Johnson, M.; Thompson, E.F.; McNamara, J. Objective Measures of Vest Therapy Adherence Among Pediatric Subjects With Cystic Fibrosis. Respir. Care 2020. [CrossRef]

8. Goodfellow, N.A.; Hawwa, A.F.; Reid, A.J.; Horne, R.; Shields, M.D.; McElnay, J.C. Adherence to treatment in children and adolescents with cystic fibrosis: A cross-sectional, multi-method study investigating the influence of beliefs about treatment and parental depressive symptoms. BMC Pulm. Med. 2015, 15, 43. [CrossRef] 
9. Ferreira, D.P.; de Miranda Chaves, C.R.M.; da Costa, A.C.C. Adherence of adolescents with cystic fibrosis to enzyme replacement therapy: Associated factors. Cien. Saude Colet. 2019, 24, 4717-4726. [CrossRef]

10. Hommel, K.A.; Rausch, J.; Towner, E.K.; Schall, J.; Maqbool, A.; Mascarenhas, M.; Stallings, V. Adherence to Nutritional Supplementation in Cystic Fibrosis. J. Pediatr. Nurs. 2019, 47, 18-22. [CrossRef]

11. VandenBranden, S.L.; McMullen, A.; Schechter, M.S.; Pasta, D.J.; Michaelis, R.L.; Konstan, M.W.; Wagener, J.S.; Morgan, W.J.; McColley, S.A. Lung function decline from adolescence to young adulthood in cystic fibrosis. Pediatr. Pulmonol. 2012, 47, 135-143. [CrossRef] [PubMed]

12. Engelen, M.P.K.J.; Com, G.; Deutz, N.E.P. Protein is an important but undervalued macronutrient in the nutritional care of patients with cystic fibrosis. Curr. Opin. Clin. Nutr. Metab. Care 2014, 17, 515-520. [CrossRef] [PubMed]

13. Dipasquale, V.; Cucinotta, U.; Romano, C. Acute Malnutrition in Children: Pathophysiology, Clinical Effects and Treatment. Nutrients 2020, 12, 2413. [CrossRef] [PubMed]

14. Yeo, M.; Sawyer, S. Chronic illness and disability. BMJ 2005, 330, 721-723. [CrossRef] [PubMed]

15. Compas, B.E.; Jaser, S.S.; Dunn, M.J.; Rodriguez, E.M. Coping with chronic illness in childhood and adolescence. Annu. Rev. Clin. Psychol. 2012, 8, 455-480. [CrossRef]

16. Poulimeneas, D.; Petrocheilou, A.; Grammatikopoulou, M.G.; Kaditis, A.G.; Loukou, I.; Doudounakis, S.E.; Laggas, D.; Vassilakou, T. High attainment of optimal nutritional and growth status observed among Greek pediatric cystic fibrosis patients: Results from the GreeCF study. J. Pediatr. Endocrinol. Metab. 2017, 30, 1169-1176. [CrossRef] [PubMed]

17. Poulimeneas, D.; Grammatikopoulou, M.G.; Petrocheilou, A.; Kaditis, A.G.; Troupi, E.; Doudounakis, S.E.; Laggas, D.; Vassilakou, T. Comparison of International Growth Standards for Assessing Nutritional Status in Cystic Fibrosis: The GreeCF Study. J. Pediatr. Gastroenterol. Nutr. 2020, 71, e35-e39. [CrossRef]

18. Kuczmarski, R.J.; Ogden, C.L.; Guo, S.S.; Grummer-Strawn, L.M.; Flegal, K.M.; Mei, Z.; Wei, R.; Curtin, L.R.; Roche, A.F.; Johnson, C.L. 2000 CDC growth charts for the United States: Methods and development. Vital Health Stat. 2002, 11, 1-190.

19. Cole, T.J.; Bellizzi, M.C.; Flegal, K.M.; Dietz, W.H. Establishing a standard definition for child overweight and obesity worldwide: International survey. BMJ 2000, 320, 1240-1243. [CrossRef]

20. Cole, T.J.; Lobstein, T. Extended international (IOTF) body mass index cut-offs for thinness, overweight and obesity. Pediatr. Obes. 2012, 7, 284-294. [CrossRef]

21. Stallings, V.A.; Stark, L.J.; Robinson, K.A.; Feranchak, A.P.; Quinton, H. Clinical Practice Guidelines on Growth and Nutrition Subcommittee; Ad Hoc Working Group Evidence-Based Practice Recommendations for Nutrition-Related Management of Children and Adults with Cystic Fibrosis and Pancreatic Insufficiency: Results of a Systematic Review. J. Am. Diet. Assoc. 2008, 108, 832-839. [CrossRef] [PubMed]

22. Willett, W. Nutritional Epidemiology; Oxford University Press: Oxford, UK, 2012; ISBN 9780199754038.

23. FAO. Dietary Assessment a Resource Guide to Method Selection and Application in Low Resource Settings; Food and Agriculture Organization of the United Nations: Rome, Italy, 2018.

24. Serra-Majem, L.; Ribas, L.; Ngo, J.; Ortega, R.M.; García, A.; Pérez-Rodrigo, C.; Aranceta, J. Food, youth and the Mediterranean diet in Spain. Development of KIDMED, Mediterranean Diet Quality Index in children and adolescents. Public Health Nutr. 2004, 7, 931-935. [CrossRef] [PubMed]

25. Štefan, L.; Prosoli, R.; Juranko, D.; Čule, M.; Milinović, I.; Novak, D.; Sporiš, G. The Reliability of the Mediterranean Diet Quality Index (KIDMED) Questionnaire. Nutrients 2017, 9, 419. [CrossRef] [PubMed]

26. Grammatikopoulou, M.G.; Gkiouras, K.; Daskalou, E.; Apostolidou, E.; Theodoridis, X.; Stylianou, C.; Galli-Tsinopoulou, A.; Tsigga, M.; Dardavessis, T.; Chourdakis, M. Growth, the Mediterranean diet and the buying power of adolescents in Greece. J. Pediatr. Endocrinol. Metab. 2018, 31, 773-780. [CrossRef] [PubMed]

27. Saxby, N.; Painter, C.; Kench, A.; King, S.; Crowder, T.; van der Haak, N. Australian and New Zealand Cystic Fibrosis Nutrition Guideline Authorship Group. In Nutrition Guidelines for Cystic Fibrosis in Australia and New Zealand; Thoracic Society of Australia and New Zealand: Syndey, Australia, 2017.

28. van der Haak, N.; King, S.J.; Crowder, T.; Kench, A.; Painter, C.; Saxby, N. Highlights from the nutrition guidelines for cystic fibrosis in Australia and New Zealand. J. Cyst. Fibros. 2020, 19, 16-25. [CrossRef]

29. Dietary Reference Values for nutrients Summary report. EFSA Support. Publ. 2017, 2017, e15121. [CrossRef]

30. Sutherland, R.; Katz, T.; Liu, V.; Quintano, J.; Brunner, R.; Tong, C.W.; Collins, C.E.; Ooi, C.Y. Dietary intake of energy-dense, nutrient-poor and nutrient-dense food sources in children with cystic fibrosis. J. Cyst. Fibros. 2018, 17, 804-810. [CrossRef] 
31. Kawchak, D.A.; Zhao, H.; Scanlin, T.F.; Tomezsko, J.L.; Cnaan, A.; Stallings, V.A. Longitudinal, prospective analysis of dietary intake in children with cystic fibrosis. J. Pediatr. 1996, 129, 119-129. [CrossRef]

32. Woestenenk, J.W.; Castelijns, S.J.A.M.; van der Ent, C.K.; Houwen, R.H.J. Dietary intake in children and adolescents with cystic fibrosis. Clin. Nutr. 2014, 33, 528-532. [CrossRef]

33. Savage, E.; Callery, P. Weight and energy: Parents' and children's perspectives on managing cystic fibrosis diet. Arch. Dis. Child. 2005, 90, 249-252. [CrossRef]

34. Geukers, V.G.M.; Oudshoorn, J.H.; Taminiau, J.A.J.M.; van der Ent, C.K.; Schilte, P.; Ruiter, A.F.C.; Ackermans, M.T.; Endert, E.; Jonkers-Schuitema, C.F.; Heymans, H.S.S.; et al. Short-term protein intake and stimulation of protein synthesis in stunted children with cystic fibrosis. Am. J. Clin. Nutr. 2005, 81, 605-610. [CrossRef] [PubMed]

35. Smith, C.; Winn, A.; Seddon, P.; Ranganathan, S. A fat lot of good: Balance and trends in fat intake in children with cystic fibrosis. J. Cyst. Fibros. 2012, 11, 154-157. [CrossRef] [PubMed]

36. Tomezsko, J.L.; Stallings, V.A.; Scanlin, T.F. Dietary Intake of Healthy Children With Cystic Fibrosis Compared With Normal Control Children. Pediatrics 1992, 90, 547-553. [PubMed]

37. Walkowiak, J.; Przyslawski, J. Five-year prospective analysis of dietary intake and clinical status in malnourished cystic fibrosis patients. J. Hum. Nutr. Diet. 2003, 16, 225-231. [CrossRef]

38. Woestenenk, J.W.; Schulkes, D.A.; Schipper, H.S.; van der Ent, C.K.; Houwen, R.H.J. Dietary intake and lipid profile in children and adolescents with cystic fibrosis. J. Cyst. Fibros. 2017, 16, 410-417. [CrossRef]

39. Kang, Z.-Q.; Yang, Y.; Xiao, B. Dietary saturated fat intake and risk of stroke: Systematic review and dose-response meta-analysis of prospective cohort studies. Nutr. Metab. Cardiovasc. Dis. 2020, 30, 179-189. [CrossRef]

40. Zhu, Y.; Bo, Y.; Liu, Y. Dietary total fat, fatty acids intake, and risk of cardiovascular disease: A dose-response meta-analysis of cohort studies. Lipids Health Dis. 2019, 18, 91. [CrossRef]

41. Aldámiz-Echevarría, L.; Prieto, J.A.; Andrade, F.; Elorz, J.; Sojo, A.; Lage, S.; Sanjurjo, P.; Vázquez, C.; Rodríguez-Soriano, J. Persistence of essential fatty acid deficiency in cystic fibrosis despite nutritional therapy. Pediatr. Res. 2009, 66, 585-589. [CrossRef]

42. Stallings, V.A.; Tindall, A.M.; Mascarenhas, M.R.; Maqbool, A.; Schall, J.I. Improved residual fat malabsorption and growth in children with cystic fibrosis treated with a novel oral structured lipid supplement: A randomized controlled trial. PLoS ONE 2020, 15, e0232685. [CrossRef]

43. Brownell, J.N.; Bashaw, H.; Stallings, V.A. Growth and Nutrition in Cystic Fibrosis. Semin. Respir. Crit. Care Med. 2019, 40, 775-791. [CrossRef]

44. Gordon, C.M.; Anderson, E.J.; Herlyn, K.; Hubbard, J.L.; Pizzo, A.; Gelbard, R.; Lapey, A.; Merkel, P.A. Nutrient Status of Adults with Cystic Fibrosis. J. Am. Diet. Assoc. 2007, 107, 2114. [CrossRef] [PubMed]

45. Figueroa, V.; Milla, C.; Parks, E.J.; Schwarzenberg, S.J.; Moran, A. Abnormal lipid concentrations in cystic fibrosis. Am. J. Clin. Nutr. 2002, 75, 1005-1011. [CrossRef] [PubMed]

46. Houston, M. The relationship of saturated fats and coronary heart disease: $\mathrm{Fa}(\mathrm{c}) \mathrm{t}$ or fiction? A commentary. Ther. Adv. Cardiovasc. Dis. 2018, 12, 33-37. [CrossRef] [PubMed]

47. Temple, N.J. Fat, Sugar, Whole Grains and Heart Disease: 50 Years of Confusion. Nutrients 2018, 10, 39. [CrossRef] [PubMed]

48. Gavin, J.; Ellis, J.; Dewar, A.L.; Rolles, C.J.; Connett, G.J. Dietary fibre and the occurrence of gut symptoms in cystic fibrosis. Arch. Dis. Child. 1997, 76, 35-37. [CrossRef] [PubMed]

49. Sabharwal, S. Gastrointestinal Manifestations of Cystic Fibrosis. Gastroenterol. Hepatol. (N. Y.) 2016, $12,43-47$.

50. Proesmans, M.; De Boeck, K. Evaluation of dietary fiber intake in Belgian children with cystic fibrosis: Is there a link with gastrointestinal complaints? J. Pediatr. Gastroenterol. Nutr. 2002, 35, 610-614. [CrossRef]

51. Pitman, R.T.; Mui, M.; Michelson, P.H.; Manary, M.J. Ready-to-Use Supplemental Food for Nutritional Supplementation in Cystic Fibrosis. Curr. Dev. Nutr. 2019, 3, nzz016. [CrossRef]

52. Hatziparasides, G.; Loukou, I.; Moustaki, M.; Douros, K. Vitamin K and cystic fibrosis: A gordian knot that deserves our attention. Respir. Med. 2019, 155, 36-42. [CrossRef]

53. Li, L.; Somerset, S. Dietary intake and nutritional status of micronutrients in adults with cystic fibrosis in relation to current recommendations. Clin. Nutr. 2016, 35, 775-782. [CrossRef]

54. Tham, A.; Katz, T.E.; Sutherland, R.E.; Garg, M.; Liu, V.; Tong, C.W.; Brunner, R.; Quintano, J.; Collins, C.; Ooi, C.Y. Micronutrient intake in children with cystic fibrosis in Sydney, Australia. J. Cyst. Fibros. 2020, 19, 146-152. [CrossRef] 
55. Grammatikopoulou, M.G.; Daskalou, E.; Hatzopoulou, M.; Sourtzinou, L.; Tsigga, M. Comparing diet composition and growth of children living in two limitary Greek islands (Samos and Corfu). Public Health Nutr. 2009, 12, 1284-1289. [CrossRef] [PubMed]

56. Manios, Y.; Moschonis, G.; Mavrogianni, C.; Bos, R.; Singh-Povel, C. Micronutrient intakes among children and adults in Greece: The role of age, sex and socio-economic status. Nutrients 2014, 6, 4073-4092. [CrossRef] [PubMed]

57. Mentella, M.C.; Scaldaferri, F.; Ricci, C.; Gasbarrini, A.; Miggiano, G.A.D. Cancer and Mediterranean Diet: A Review. Nutrients 2019, 11, 2059. [CrossRef] [PubMed]

58. Poulimeneas, D.; Anastasiou, C.A.; Santos, I.; Hill, J.O.; Panagiotakos, D.B.; Yannakoulia, M. Exploring the relationship between the Mediterranean diet and weight loss maintenance: The MedWeight study. Br. J. Nutr. 2020, 124, 874-880. [CrossRef]

59. Cano, A.; Marshall, S.; Zolfaroli, I.; Bitzer, J.; Ceausu, I.; Chedraui, P.; Durmusoglu, F.; Erkkola, R.; Goulis, D.G.; Hirschberg, A.L.; et al. The Mediterranean diet and menopausal health: An EMAS position statement. Maturitas 2020, 139, 90-97. [CrossRef]

60. Grammatikopoulou, M.G.; Lampropoulou, M.; Goulis, D.G. Mediterranean diet and female fertility: Cross-talk of an evidence-based approach. In The Mediterranean Diet: An Evidence-Based Approach; Preedy, V.R., Watson, R.R., Eds.; Elsevier: London, UK, 2020; pp. 473-483.

61. Strandvik, B. Mediterranean diet and cystic fibrosis. Br. J. Nutr. 2006, 96, 199-200. [CrossRef]

62. Gutiérrez-Carrasquilla, L.; Sánchez, E.; Hernández, M.; Polanco, D.; Salas-Salvadó, J.; Betriu, À.; Gaeta, A.M.; Carmona, P.; Purroy, F.; Pamplona, R.; et al. Effects of Mediterranean Diet and Physical Activity on Pulmonary Function: A Cross-Sectional Analysis in the ILERVAS Project. Nutrients 2019, 11, 329. [CrossRef]

63. Grammatikopoulou, M.G.; Gkiouras, K.; Tranidou, A.; Goulis, D.G. Food security and adherence to the Mediterranean diet: An interplay of socio-demographic characteristics. In The Mediterranean Diet: An Evidence-Based Approach; Preedy, V.R., Watson, R.R., Eds.; Elsevier: London, UK, 2020; pp. 79-88. ISBN 9780128186497.

64. Tsakiraki, M.; Grammatikopoulou, M.G.; Stylianou, C.; Tsigga, M. Nutrition transition and health status of Cretan women: Evidence from two generations. Public Health Nutr. 2011, 14, 793-800. [CrossRef]

65. Lydakis, C.; Stefanaki, E.; Stefanaki, S.; Thalassinos, E.; Kavousanaki, M.; Lydaki, D. Correlation of blood pressure, obesity, and adherence to the Mediterranean diet with indices of arterial stiffness in children. Eur. J. Pediatr. 2012, 171, 1373-1382. [CrossRef]

66. GBD 2017 Diet Collaborators. Health effects of dietary risks in 195 countries, 1990-2017: A systematic analysis for the Global Burden of Disease Study 2017. Lancet 2019, 393, 1958-1972. [CrossRef]

67. Foster, E.; Bradley, J. Methodological considerations and future insights for 24-hour dietary recall assessment in children. Nutr. Res. 2018, 51, 1-11. [CrossRef] [PubMed]

(C) 2020 by the authors. Licensee MDPI, Basel, Switzerland. This article is an open access article distributed under the terms and conditions of the Creative Commons Attribution (CC BY) license (http://creativecommons.org/licenses/by/4.0/). 